\title{
An evaluation of the impact of patient cost sharing for antihypertensive medications on adherence, medication and health care utilization, and expenditures
}

\author{
This article was published in the following Dove Press journal: \\ Patient Preference and Adherence \\ 17 January 2012 \\ Number of times this article has been viewed
}

\author{
Jacqueline A Pesa' \\ Jill Van Den Bos ${ }^{2}$ \\ Travis Gray² \\ Colleen Hartsig² \\ Robert Brett McQueen ${ }^{3}$ \\ Joseph J Saseen ${ }^{3}$ \\ Kavita $\bigvee \mathrm{Nair}^{3}$ \\ 'Janssen Scientific Affairs, LLC, \\ Louisville, CO, USA; ${ }^{2}$ Milliman, Inc, \\ Denver, CO, USA; ${ }^{3}$ University \\ of Colorado Anschutz Medical \\ Campus, Aurora, CO, USA
}

Correspondence: Kavita V Nair

Center for Pharmaceutical Outcomes Research, University of Colorado Anschutz Medical Campus, School of Pharmacy Mail Stop C238, I 2850 E.

Montview Blvd, Room V20-1202,

Aurora, CO 80045, USA

Tel +l 3037242635

Fax + I 3037240979

Email kavita.nair@ucdenver.edu
Objective: To assess the impact of patient cost-sharing for antihypertensive medications on the proportion of days covered (PDC) by antihypertensive medications, medical utilization, and health care expenditures among commercially insured individuals assigned to different risk categories.

Methods: Participants were identified from the Consolidated Health Cost Guidelines (CHCG) database (January 1, 2006-December 31, 2008) based on a diagnosis (index) claim for hypertension, continuous enrollment $\geq 12$ months pre- and post-index, and no prior claims for antihypertensive medications. Participants were assigned to: low-risk group (no comorbidities), high-risk group (1+ selected comorbidities), or very high-risk group (prior hospitalization for $1+$ selected comorbidities). The relationship between patient cost sharing and PDC by antihypertensive medications was assessed using standard linear regression models, controlling for risk group membership, and various demographic and clinical factors. The relationship between PDC and health care service utilization was subsequently examined using negative binomial regression models.

Results: Of the 28,688 study patients, $66 \%$ were low risk. The multivariate regression model supported a relationship between patient cost sharing per 30-day fill and PDC in the following year. For every US\$1.00 increase in cost sharing, PDC decreased by 1.1 days $(P<0.0001)$. Significant predictors of PDC included high risk, older age, gender, Charlson Comorbidity Index score, geography, and total post-index insurer- and patient-paid costs. An increase in PDC was associated with a decrease in all-cause and hypertension-related inpatient, outpatient, and emergency room visits and medical, pharmacy, and total costs.

Conclusions: The trend has been for managed care organizations and employers to require patients to bear a greater out-of-pocket burden for health care resources consumed. This study illustrates the potential adverse effects of higher patient cost sharing among patients with hypertension stratified by different risk levels. A decrease in PDC was predictive of higher resource utilization and health care costs, which should be of interest to payers and employers alike.

Keywords: hypertension, adherence, cost sharing, outcomes

\section{Background}

The Centers for Disease Control and Prevention estimates that one in three US adults has hypertension, ${ }^{1,2}$ and Framingham data estimate that $90 \%$ of nonhypertensive individuals aged 55 years or older will eventually develop hypertension in their lifetime. ${ }^{3}$ Costs in terms of health care services, medication, and reduced 
productivity totaled US\$76.6 billion for hypertension in the US in $2010 .{ }^{4}$ Although a variety of evidence-based medications are available for the treatment and control of hypertension, these drugs will be ineffective if patients do not adhere to their prescribed regimens. Poor adherence to antihypertensive medication has been linked to poor blood pressure control, rehospitalization, and increased health care resource utilization. On the other hand, increased adherence to antihypertensive medication has been shown to reduce hospitalization risk and health care costs, and is therefore likely to decrease productivity loss due to chronic conditions. ${ }^{5}$

The management of hypertension presents an interesting challenge for the following reasons: (1) there are multiple drug classes available to treat the disease ranging from inexpensive diuretics to brand-name combination therapies and the newer direct renin inhibitors; (2) hypertension is a major independent risk factor for several comorbid conditions, namely coronary artery disease, chronic kidney disease, diabetes, and ischemic stroke; ${ }^{6}(3)$ patients are generally on multiple medications to manage their hypertension, creating a financial burden due to out-of-pocket expenditures; ${ }^{7}$ and (4) as hypertension is an asymptomatic disease, adherence rates are low according to some estimates, ranging from $36 \%-80 \%{ }^{8}$ Poor medication adherence among hypertensive patients is one of the primary causes of the failure to achieve adequate control of blood pressure. ${ }^{9}$ The low rates of adherence to antihypertensive medication are mainly due to the complexity of dosing regimens and the side-effect profiles of the drugs, ${ }^{9}$ but poor adherence is also attributable to the asymptomatic nature of the disease, the fact that the condition is chronic, and the ensuing economic burden that many patients must share with third-party payers over the long term. ${ }^{10}$

As organizations grapple with the high cost of health care, policies to shift costs to patients have become the norm. In response, a body of literature has arisen that attempts to examine the impact of these cost shifts on outcomes. Since hypertension is a prevalent and chronic condition with a high cost burden, extensive research has been conducted to assess the impact of cost sharing on antihypertensive medication adherence. ${ }^{11-16}$ While the methods employed and populations examined vary widely, overwhelmingly these studies support a negative relationship between patient cost sharing in various forms and medication adherence. Chernew and colleagues $^{12}$ found that medication adherence increased after copays were reduced for common antihypertensive medications. A 2010 study of military veterans found that a
US $\$ 5$ copayment increase (from US\$2 to US\$7) adversely impacted adherence to antihypertensive medications. ${ }^{13}$ In the same year, Maciejewski and colleagues examined the effects of eliminating copayments for generic medications and reducing copayments for brand-name medications, and found that adherence improved by 1.5 percentage points for patients with hypertension taking calcium-channel blockers. ${ }^{15}$ Most recently, a retrospective study of employees of a large global pharmaceutical firm showed that reduced cost sharing was associated with increased medication adherence, with the greatest improvement observed among employees taking cardiovascular medications. ${ }^{14}$

Building upon previous research, this study assessed the impact of patient cost sharing in the form of 30-day copays for antihypertensive medications on proportion of days covered (PDC, used as the proxy for adherence) during the 12-month post-index period. Additionally, the impact of adherence to antihypertensive medications on medical utilization outcomes and health care expenditures for individuals with hypertension was assessed. The impetus for this research was an apparent gap in the literature, ie, no published study in this area applied an approach to stratify patients by "risk level" (as defined by measures of comorbidity) to determine whether risk level tempers or exacerbates the impact of cost sharing on adherence. This is an important aspect, given that comorbidity is often included as a covariate in similar studies in order to neutralize the independent effect of this variable on the outcome (adherence). By understanding how comorbidity risk level impacts the relationship between cost sharing and adherence, policy makers, health plans, and employers should be better positioned to create targeted policies.

\section{Methods \\ Data source}

Data for this study were obtained from the 2007 and 2008 Consolidated Health Cost Guidelines database (CHCG) developed by Milliman. ${ }^{17}$ This database is used by Milliman to produce its Health Cost Guidelines tool used by payers nationwide to price health care benefits, set benchmarks, measure the impact of health plan changes, and manage health care utilization. It has also been used to conduct simulations that allow for estimation of the effects of health benefit modifications and evaluation of the risks and benefits of alternative benefit approaches. The current database contains medical, pharmacy, and enrollment data from 2004-2007 for roughly 15 million patients, 2 million of whom had a diagnosis of hypertension at the time of the study sample identification period. 


\section{Sample selection}

In order to be included in the study, members were identified from the CHCG database based on the following criteria:

- $\geq 2$ outpatient visits or $\geq 1$ emergency room visit or $\geq 1$ hospitalization with hypertension as the primary or secondary International Classification of Diseases, Ninth Revision (ICD-9) code of 401xx, 402xx, 403xx, 404xx, or 405xx; and

- $\geq 12$ months of continuous enrollment prior to the index diagnosis claim for hypertension (baseline period) and a minimum of 12 months of continuous enrollment following the index diagnosis claim for hypertension (follow-up period); and

- No antihypertensive medication claims preceding the date of the first hypertension diagnosis; and

- At least one prescription for a hypertensive medication following the diagnosis for hypertension.

\section{Primary outcome measures}

\section{Pharmacy-based outcome measures}

The pharmacy-based measures consisted of annualized measurements per member per year (PMPY) for: (a) the number of hypertension medications (any, brand, generic), and (b) medication adherence, defined as the PDC for antihypertensive medications. The PDC was calculated as the number of days with any antihypertensive medication divided by the number of days in the follow-up period for each patient. ${ }^{18}$ Use of refills for antihypertensive medications was determined using a set of rules to avoid double-counting covered days. For example, when a prescription for an antihypertensive medication was issued before the previous antihypertensive prescription should have run out, use of the new prescription was assumed to begin the day after the end of the old prescription and the days' supply for the new prescription was appended to the end of the previous fill. Any surplus days' supply remaining on the last day of the observation period was truncated. The PDC could only have a value between 0 and 1 and was multiplied by $100 \%$ to derive the percentage. On the basis of their PDC, patients were assigned an adherence value ranging from $0 \%-100 \%$.

\section{Medical utilization-based outcome measures}

The number of hypertension-related emergency room visits, outpatient visits, and laboratory or diagnostic visits during the pre-index and post-index periods was determined for each patient.

\section{Expenditure-based outcome measures}

Expenditure-based measures consisted of health plan pharmacy expenditures for antihypertensive medications, patient out-of-pocket costs for antihypertensive medications, and health plan expenditures for hypertension-related medical services for each of the three hypertension risk groups. Total health care and pharmacy expenditures for all services and prescriptions were computed in a similar manner.

\section{Cohort assignment}

Patients were assigned to one of the following risk groups based on the following criteria:

- Low risk: a diagnosis claim for hypertension but no comorbid conditions (see below) during the pre-index and post-index periods.

- High risk: a diagnosis claim for hypertension and a diagnosis claim for 1 or more comorbid conditions (see below) during the pre-index or post-index periods.

- Very high risk: a diagnosis claim for hypertension along with a hospitalization for 1 or more comorbid conditions (see below) during the pre-index or post-index periods. The following comorbid conditions were applied in the categorization of risk groups:

- Diabetes (ICD-9 250xx)

- Heart disease (ICD-9 410xx, 414xx)

- Chronic kidney disease (ICD-9 585xx, 586xx, 403xx, 404xx)

- Ischemic stroke (ICD-9 430xx, 431xx, 432xx 433xx, $434 \mathrm{xx})$

- Depression (ICD-9 296xx, 311xx, 3004x)

- Asthma (ICD-9 433xx, 440xx)

- Pulmonary vascular disease (ICD-9 443xx)

- Dyslipidemia (ICD-9 2724x).

\section{Covariates}

Covariates included in the regression models included age, gender, Charlson Comorbidity Index (CCI) score, geographic region of health plan enrollment, health insurance plan type, income (based on assignment by zip code from the US Census Bureau), patient cost sharing for antihypertensive medications and hypertension-related medical services, and plan-paid medical expenditures for hypertension-related services.

\section{Analysis: models}

Models were created to evaluate treatment adherence (measured as the number of days covered by a prescription for an antihypertensive medication in the year following diagnosis), health care service utilization (inpatient, ER, outpatient), and total allowed health care service cost (medical, pharmaceutical, total cost). For the adherence 
regressions, we used a standard linear regression. For the utilization regressions, we used a zero-adjusted negative binomial model for lower frequency events and a negative binomial model for more frequent events. We considered Poisson models, but examination of the response variables showed that the binomial distribution provided a better description of the response variables. For costs, we created six models that predicted medical, pharmaceutical, and overall costs, both for hypertension-related services and all services. These regressions used a log-transformed response variable to produce a better fit.

\section{Results}

The characteristics of the overall sample and the defined risk groups are presented in Table 1. There were 28,688 individuals who met the inclusion criteria, with the majority $(66 \%)$ in the low-risk group $(n=18,937)$. The average age of the sample population was 49.5 years, with slightly fewer females (45.6\%), and an estimated average annual income of US\$41,964. The majority of the sample members resided in the South (36\%) or Midwest (33.6\%) and were enrolled in a preferred provider organization (PPO [76.5\%]). By definition, the low-risk group did not have any members with the selected comorbidities, while in the very high-risk group, these conditions were prevalent (particularly dyslipidemia, diabetes, and heart disease). Patient cost-sharing and insurerpaid costs for antihypertensive medications were identical, averaging US\$96 per month. The mean number of distinct antihypertensive medications in the 12-month follow-up period was 1.38 , with prescriptions for branded agents averaging 1.73 and generics 5.75, respectively. The Charlson Comorbidity Index score was 0.58 across the overall sample, with the very high-risk group having the greatest comorbidity burden, as expected. The average number of days over the 12-month follow-up period that patients in our study population received an antihypertensive drug (adherence) was 205 days (PDC 56\%), with little difference between the three risk groups.

Characteristics of the study participants by risk group in terms of pre-index and post-index medication history and hypertension-related and all-cause health care expenditures (resources used, insurer-paid costs, and patient-paid costs) are shown in Table 2. With increasing risk, the number of medications, health care events, and costs increased. In most cases, both insurer-paid and patient-paid all-cause costs increased from the pre-index to post-index periods. Hypertension-related costs in the post-index period were mostly borne by the insurer, and were relatively low.
In order to determine the relationship between cost sharing and adherence (ie, PDC), a multivariate regression model was constructed, controlling for the potential effects of factors that may have an independent relationship with adherence. Table 3 describes each covariate and offers the rationale for inclusion along with key supporting references. The full results of our model are presented in Table 4. For every US\$1.00 increase in patient cost sharing per fill (30 days), the number of days in the year that a patient was covered by an antihypertensive medication decreased by 1.10 days $(P<0.0001)$. Risk group status was a significant predictor of adherence for those who were defined as "high risk" compared to the reference "low risk" group. High-risk patients essentially were adherent for 7.78 more days $(P<0.0001)$. There was a general trend toward improved adherence with age, with the exception of the oldest group examined (ages 56-65). Gender was a significant predictor of days adherent: males had approximately 3 fewer days of adherence compared with women $(P=0.045)$. The Charlson Comorbidity Index risk score also influenced adherence: for every point increase, adherence decreased by 6.23 days $(P<0.0001)$. Compared with residence in the western part of the US, residing in the South, Midwest, and Northeast was associated with a decrease in number of days adherent $(P<0.0001)$. Total costs paid by the insurer in both the pre-index and post-index periods were weakly associated with our dependent variable, as were total costs paid by the patient.

In an effort to further explore the relationship between the number of days patients were adherent to antihypertensive medications and resource utilization in the 12-month post-index period, a series of eleven zero-inflated negative binomial regression models were constructed (data not shown). The dependent variables for these models included: all-cause and hypertension-related outpatient costs, allcause and hypertension-related inpatient costs, all-cause and hypertension-related pharmacy costs, all-cause and hypertension-related outpatient costs, ER utilization, total allcause and hypertension-related medical costs, total all-cause and hypertension-related pharmacy costs, total all-cause and hypertension-related medical plus pharmacy costs. The covariates included in each regression model were identical to those included in the previous models, which are fully described in Table 3 . The results of this series of analyses suggest a beneficial association between the number of days patients were adherent to antihypertensive medication and economic outcomes. For example, the model which examined the impact of the number of days that patients were adherent to antihypertensive medication on total medical 
Table I Sample characteristics

\begin{tabular}{|c|c|c|c|c|}
\hline & Low risk & High risk & Very high risk & Overall \\
\hline Number of persons, $N(\%)$ & $18,937(66.0 \%)$ & $8057(28.1 \%)$ & $1694(5.9 \%)$ & 28,688 \\
\hline Average age, years & 48.2 & 51.6 & 54.4 & 49.5 \\
\hline Female, N (\%) & 8979 (47.4\%) & $3512(43.6 \%)$ & $589(34.8 \%)$ & I3,080 (45.6\%) \\
\hline Average income, US\$ & $\$ 42,026$ & $\$ 41,907$ & $\$ 4 I, 544$ & $\$ 41,964$ \\
\hline \multicolumn{5}{|l|}{ Region of residence, N (\%) } \\
\hline Northeast & $230 \mathrm{I}(12.2 \%)$ & II 55 (I4.3\%) & 322 (19.0\%) & $3778(13.2 \%)$ \\
\hline Midwest & $6244(33.0 \%)$ & $2775(34.4 \%)$ & $617(36.4 \%)$ & $9636(33.6 \%)$ \\
\hline South & $6995(36.9 \%)$ & $2776(34.5 \%)$ & $565(33.4 \%)$ & $10,336(36.0 \%)$ \\
\hline West & 3397 (I7.9\%) & I35I (I6.8\%) & 190 (I I.2\%) & $4938(17.2 \%)$ \\
\hline \multicolumn{5}{|l|}{ Comorbid conditions, N (\%) } \\
\hline Diabetes & $0(0.0 \%)$ & $24 I I(29.9 \%)$ & $586(34.6 \%)$ & 2997 (10.4\%) \\
\hline Heart disease & $0(0.0 \%)$ & $562(7.0 \%)$ & 781 (46.1\%) & I 343 (4.7\%) \\
\hline Chronic kidney disease & $0(0.0 \%)$ & $222(2.8 \%)$ & $107(6.3 \%)$ & $329(1.1 \%)$ \\
\hline Ischemic stroke & $0(0.0 \%)$ & $182(2.3 \%)$ & $350(20.7 \%)$ & $532(1.9 \%)$ \\
\hline Depression N & $0(0.0 \%)$ & $1314(16.3 \%)$ & $310(18.3 \%)$ & $1624(5.7 \%)$ \\
\hline Atherosclerosis & $0(0.0 \%)$ & $194(2.4 \%)$ & $206(12.2 \%)$ & $400(1.4 \%)$ \\
\hline Peripheral vascular disease & $0(0.0 \%)$ & $120(1.5 \%)$ & $87(5.1 \%)$ & $207(0.7 \%)$ \\
\hline Dyslipidemia & $0(0.0 \%)$ & $4734(58.8 \%)$ & $646(38.1 \%)$ & $5380(18.8 \%)$ \\
\hline Average antihypertensive medication costs paid by insurer & $\$ 88$ & $\$ 111$ & $\$ 117$ & $\$ 96$ \\
\hline Average antihypertensive medication costs paid by patient & $\$ 93$ & $\$ 100$ & $\$ 103$ & $\$ 96$ \\
\hline Number of distinct antihypertensive drugs & 1.35 & 1.39 & $\mathrm{I} .74$ & 1.38 \\
\hline Average antihypertensive drug days per year & 204 & 211 & 200 & 205 \\
\hline Average \# brand name antihypertensive prescriptions & 1.68 & 1.85 & 1.77 & 1.73 \\
\hline Average \# generic antihypertensive prescriptions & 5.61 & 5.81 & 7.05 & 5.75 \\
\hline Mean Charlson Comorbidity Index score & 0.32 & 0.85 & 2.11 & 0.58 \\
\hline \multicolumn{5}{|l|}{ Health insurance plan type, $N(\%)$} \\
\hline Comprehensive major medical/traditional & $|48|(7.8 \%)$ & $706(8.8 \%)$ & $211(12.5 \%)$ & $2398(8.4 \%)$ \\
\hline Point of service & $900(4.8 \%)$ & $381(4.7 \%)$ & $60(3.5 \%)$ & |34| (4.7\%) \\
\hline Preferred provider organization & |4,537 (76.8\%) & $6168(76.6 \%)$ & 1240 (73.2\%) & $21,945(76.5 \%)$ \\
\hline Health maintenance organization & $2019(10.7 \%)$ & 802 (10.0\%) & 183 (10.8\%) & 3004 (10.5\%) \\
\hline
\end{tabular}

costs revealed that, on average, a 1-day increase in the total number of days adherent to antihypertensive medication was associated with a $0.13 \%$ decrease in total medical costs. The directionality of this relationship was similar for each model. An increase in the number of days adherent to antihypertensive medication was associated with a decrease in both all-cause and hypertension-related utilization of inpatient, outpatient, and emergency room visits as well as medical, pharmacy, and total costs.

\section{Discussion}

As organizations grapple with the high cost of health care, programs and policies have been enacted in an attempt to reduce the burden. Policies enacted by payers include increasing patient copays and coinsurance for non-preferred or branded medications. More holistic approaches have been put into place by employers, and include reducing and/or eliminating patient copays for medications used to treat chronic conditions, the rationale being that, by promoting the use of these needed therapies, adherence will improve and patients will be less likely to require costly medical treatment down the road. This study supports that notion. Triggered by questions around the economic and clinical impact of these policies and programs, a body of literature now exists that effectively provides evidence of the benefits and challenges. Given the prevalence, chronicity, and economic impact of hypertension, many studies have been conducted to assess the impact of patient cost sharing specifically on antihypertensive medication adherence, ${ }^{11,12,15,16}$ while others have broadened the approach to target other cardiovascular conditions, such as diabetes. ${ }^{14}$

Recently, employers have been implementing creative strategies to improve the health of employees with chronic conditions and to rein in costs. "Value-based programs" and "value-based benefit design" are phrases used to describe these programs. The National Business Coalition on Health defines value-based benefit design as "the explicit use of employee benefit incentives to encourage people to adopt appropriate use of high-value health services, adopt healthy lifestyles, and select high performance providers."19 
Table 2 Sample characteristics: medications, health care expenditures, and events

\begin{tabular}{|c|c|c|c|c|}
\hline & Low risk & High risk & Very high risk & Overall \\
\hline \multicolumn{5}{|l|}{ Total generic medications } \\
\hline \multicolumn{5}{|l|}{ Pre-index } \\
\hline Total generic medications, pre index & 3.18 & 4.32 & 4.62 & 3.59 \\
\hline Total medication costs paid by insurer, pre-index & $\$ 4 I I$ & $\$ 772$ & $\$ 745$ & $\$ 532$ \\
\hline Total medication costs paid by patient, pre-index & $\$ 146$ & $\$ 241$ & $\$ 246$ & $\$ 179$ \\
\hline \multicolumn{5}{|l|}{ Post-index } \\
\hline Total number of generic medications, post-index & 6.20 & 8.09 & 11.12 & 7.02 \\
\hline Total medication costs paid by insurer, post-index & $\$ 762$ & $\$ 1386$ & $\$ 1996$ & $\$ 1010$ \\
\hline Total medication costs paid by patient, post-index & $\$ 316$ & $\$ 498$ & $\$ 700$ & $\$ 390$ \\
\hline \multicolumn{5}{|l|}{ All inpatient visits } \\
\hline \multicolumn{5}{|l|}{ Pre-index } \\
\hline Annual events & 0.06 & 0.08 & 0.38 & 0.08 \\
\hline Insurer paid & $\$ 517$ & $\$ 747$ & $\$ 6,111$ & $\$ 912$ \\
\hline Patient paid & $\$ 52$ & $\$ 89$ & $\$ 323$ & $\$ 78$ \\
\hline \multicolumn{5}{|l|}{ Post-index } \\
\hline Annual events & 0.14 & 0.19 & 1.39 & 0.23 \\
\hline Insurer paid & $\$ 1267$ & $\$ 1839$ & $\$ 20,826$ & $\$ 2583$ \\
\hline Patient paid & $\$ 107$ & $\$ 145$ & $\$ 1009$ & $\$ 17 \mid$ \\
\hline \multicolumn{5}{|l|}{ All emergency room visits } \\
\hline \multicolumn{5}{|l|}{ Pre-index } \\
\hline Annual events & 0.41 & 0.43 & 1.31 & 0.47 \\
\hline Insurer paid & $\$ 82$ & $\$ 89$ & $\$ 442$ & $\$ 106$ \\
\hline Patient paid & $\$ 27$ & $\$ 29$ & $\$ 97$ & $\$ 32$ \\
\hline \multicolumn{5}{|l|}{ Post-index } \\
\hline Annual events & 0.66 & 0.66 & 3.00 & 0.80 \\
\hline Insurer paid & $\$ 158$ & $\$ 180$ & $\$ 1162$ & $\$ 223$ \\
\hline Patient paid & $\$ 47$ & $\$ 43$ & $\$ 233$ & $\$ 57$ \\
\hline \multicolumn{5}{|l|}{ All outpatient visits } \\
\hline \multicolumn{5}{|l|}{ Pre-index } \\
\hline Annual events & 7.15 & 10.29 & 12.27 & 8.33 \\
\hline Insurer paid & $\$ 834$ & $\$ 1368$ & $\$ 1509$ & $\$ 1024$ \\
\hline Patient paid & $\$ 221$ & $\$ 299$ & $\$ 347$ & $\$ 250$ \\
\hline \multicolumn{5}{|l|}{ Post-index } \\
\hline Annual events & $|3.5|$ & 17.86 & 31.88 & 15.82 \\
\hline Insurer paid & $\$ 1776$ & $\$ 2587$ & $\$ 5438$ & $\$ 2220$ \\
\hline Patient paid & $\$ 434$ & $\$ 568$ & $\$ 735$ & $\$ 489$ \\
\hline \multicolumn{5}{|l|}{ All laboratory/diagnostic tests } \\
\hline \multicolumn{5}{|l|}{ Pre-index } \\
\hline Annual events & 3.66 & 5.25 & 7.11 & 4.31 \\
\hline Insurer paid & $\$ 417$ & $\$ 543$ & $\$ 809$ & $\$ 475$ \\
\hline Patient paid & $\$ 92$ & $\$ 122$ & $\$ 156$ & $\$ 104$ \\
\hline \multicolumn{5}{|l|}{ Post-index } \\
\hline Annual events & 7.79 & 10.88 & 18.52 & 9.29 \\
\hline Insurer paid & $\$ 862$ & $\$ 1137$ & $\$ 2316$ & $\$ 1025$ \\
\hline Patient paid & $\$ 178$ & $\$ 222$ & $\$ 290$ & $\$ 197$ \\
\hline \multicolumn{5}{|l|}{ All other annual events } \\
\hline \multicolumn{5}{|l|}{ Pre-index } \\
\hline Annual events & 1.05 & 1.49 & 2.57 & 1.26 \\
\hline Insurer paid & $\$ 155$ & $\$ 216$ & $\$ 390$ & $\$ 186$ \\
\hline Patient paid & $\$ 32$ & $\$ 42$ & $\$ 54$ & $\$ 36$ \\
\hline Post-index & & & & \\
\hline Annual events & 1.71 & 2.44 & 6.42 & 2.20 \\
\hline Insurer paid & $\$ 353$ & $\$ 520$ & $\$ 1537$ & $\$ 470$ \\
\hline Patient paid & $\$ 55$ & $\$ 67$ & $\$ 139$ & $\$ 64$ \\
\hline HTN inpatient visits, post- index & & & & \\
\hline Annual events & 0.02 & 0.03 & 0.24 & 0.03 \\
\hline Insurer paid & $\$ 187$ & $\$ 311$ & $\$ 4591$ & $\$ 482$ \\
\hline Patient paid & $\$ 14$ & $\$ 28$ & $\$ 194$ & $\$ 29$ \\
\hline
\end{tabular}


Table 2 (Continued)

\begin{tabular}{|c|c|c|c|c|}
\hline & Low risk & High risk & Very high risk & Overall \\
\hline \multicolumn{5}{|c|}{ HTN emergency room visits, post-index } \\
\hline Annual events & 0.05 & 0.04 & 0.10 & 0.05 \\
\hline Insurer paid & $\$ 9$ & $\$ 6$ & $\$ 21$ & $\$ 8$ \\
\hline Patient paid & $\$ 5$ & $\$ 3$ & $\$ 7$ & $\$ 4$ \\
\hline \multicolumn{5}{|c|}{ HTN outpatient visits, post-index } \\
\hline Annual events & 3.76 & 3.98 & 3.72 & 3.82 \\
\hline Insurer paid & $\$ 288$ & $\$ 355$ & $\$ 438$ & $\$ 316$ \\
\hline Patient paid & $\$ 98$ & $\$ 100$ & $\$ 92$ & $\$ 98$ \\
\hline \multicolumn{5}{|c|}{ HTN laboratory/ diagnostic tests, post-index } \\
\hline Annual events & 1.99 & 2.48 & 2.15 & 2.14 \\
\hline Insurer paid & $\$ 105$ & $\$ 130$ & $\$ 178$ & $\$ 116$ \\
\hline Patient paid & $\$ 32$ & $\$ 36$ & $\$ 42$ & $\$ 34$ \\
\hline \multicolumn{5}{|c|}{ HTN other annual events, post-index } \\
\hline Annual events & 0.19 & 0.18 & 0.43 & 0.20 \\
\hline Insurer paid & $\$ 24$ & $\$ 33$ & $\$ 97$ & $\$ 30$ \\
\hline Patient paid & $\$ 5$ & $\$ 5$ & $\$ 9$ & $\$ 5$ \\
\hline
\end{tabular}

Abbreviation: HTN, hypertension.

A value-based program enacted by Blue Cross Blue Shield of North Carolina eliminated generic medication copayments and reduced copayments from tier 3 to tier 2 pricing for brandname medications in eight therapeutic classes for the treatment of cardiovascular disease, including hypertension. ${ }^{13}$ Using a propensity-matched design, adherence improved for employees exposed to the program for medications for diabetes, hypertension, hyperlipidemia, and congestive heart failure. Chernew and colleagues ${ }^{12}$ evaluated the outcomes associated with another value-based program enacted by a large employer and found that medication adherence increased after patient copays were reduced for medications in five classes (including those commonly used to treat hypertension: angiotensin- converting enzyme inhibitors, angiotensin receptor blockers, and beta blockers) within the context of a disease management program. Copays for generic medications were reduced from US\$5 to US\$0 and from US\$25 to US $\$ 12.50$ for preferred brand name medications, and from US\$45 to US\$22.50 for non-preferred medications. Holding the influence of the disease management program constant in their analysis, there was a clear positive effect of the intervention on adherence to antidiabetic agents, beta-blockers, and angiotensin converting enzyme (ACE) inhibitors/angiotensin receptor blockers (ARBs) (reducing nonadherence by $7 \%-14 \%$ ).

The low adherence rate of 56\% (205 days per year) that we observed in our patient sample corroborates

Table 3 Covariates in regression models

\begin{tabular}{|c|c|c|}
\hline Variable & Description & Justification \\
\hline Cost sharing & $\begin{array}{l}\text { Continuous variable in } 2008 \text { US dollars, patient } \\
\text { cost sharing per } 30 \text {-day fill }\end{array}$ & $\begin{array}{l}\text { Cost sharing tiers may affect utilization } \\
\text { and adherence to medications }{ }^{34}\end{array}$ \\
\hline Risk group & $\begin{array}{l}3 \text { groups }^{\dagger} \text { : very high risk, high risk, and low risk } \\
\text { as the reference group }\end{array}$ & $\begin{array}{l}\text { Risk of complications and medication } \\
\text { adherence are often related and must } \\
\text { be controlled for }\end{array}$ \\
\hline Gender & $\begin{array}{l}\text { Binary variable, male }=1 \text {, and female as the } \\
\text { reference group }\end{array}$ & Gender may be related to adherence \\
\hline Age & $\begin{array}{l}7 \text { groups }^{\dagger}:<17,18-25,26-35,36-45,46-55, \\
56-65, \text { and }>65 \text { as the reference group }\end{array}$ & $\begin{array}{l}\text { Adherence to medications may be } \\
\text { age-related }\end{array}$ \\
\hline Region & $\begin{array}{l}4 \text { groups }^{\dagger} \text { : South, Midwest, Northeast, and West } \\
\text { as the reference group }\end{array}$ & Demographic control variable \\
\hline Medical costs paid by insurer & Log of medical costs paid by insurer & $\begin{array}{l}\text { Share of medical costs is associated with } \\
\text { decreased adherence levels }{ }^{35}\end{array}$ \\
\hline Medical costs paid by patient & Log of medical costs paid by patient & $\begin{array}{l}\text { Share of medical costs is associated with } \\
\text { decreased adherence levels }{ }^{35}\end{array}$ \\
\hline Charlson Comorbidity Index score & $\begin{array}{l}\text { Index score variable treated as a continuous } \\
\text { variable }\end{array}$ & $\begin{array}{l}\text { Serves as a proxy for severity of disease } \\
\text { and may serve as a predictor for mortality }{ }^{36}\end{array}$ \\
\hline
\end{tabular}

Note: ${ }^{\dagger}$ All groups are mutually exclusive and exhaustive. 
Table 4 Predictors of days adherent to antihypertensive medication

\begin{tabular}{|c|c|c|c|c|}
\hline Variable & Parameter estimate & Standard error & $\mathbf{T}$ value & Prob $>t$ \\
\hline Intercept & 214.54 & 4.76 & 45.01 & $<0.0001$ \\
\hline Cost sharing & -1.10 & 0.06 & -18.28 & $<0.0001$ \\
\hline High risk ${ }^{\dagger}$ & 7.78 & 1.52 & 5.13 & $<0.0001$ \\
\hline Very high risk ${ }^{\dagger}$ & -3.14 & 3.15 & -1.00 & 0.319 \\
\hline Male $^{\S}$ & -2.67 & 1.33 & -2.01 & 0.045 \\
\hline \multicolumn{5}{|l|}{ Age group (years) $)^{\ddagger}$} \\
\hline$\leq 17$ & -29.02 & 9.56 & -3.03 & 0.002 \\
\hline $18-25$ & -20.81 & 6.29 & -3.31 & 0.000 \\
\hline $26-35$ & -10.99 & 3.76 & -2.92 & 0.004 \\
\hline $36-45$ & 5.38 & 3.30 & 1.63 & 0.104 \\
\hline $46-55$ & 19.19 & 3.19 & 6.01 & $<0.0001$ \\
\hline $56-65$ & 16.18 & 3.25 & 4.97 & $<0.0001$ \\
\hline South* & -57.52 & 1.97 & -29.23 & $<0.0001$ \\
\hline Midwest* & -36.26 & 1.93 & -18.75 & $<0.0001$ \\
\hline Northeast* & -39.06 & 2.41 & -16.19 & $<0.0001$ \\
\hline Total paid by insurer, pre-index & -0.28 & 0.39 & -0.71 & 0.477 \\
\hline Total paid by patient, pre-index & -0.87 & 0.46 & -1.88 & 0.059 \\
\hline Total paid by insurer, post-index & -2.85 & 0.47 & -6.13 & $<0.0001$ \\
\hline Total paid by patient, post-index & 1.25 & 0.58 & 2.16 & 0.030 \\
\hline Charlson Comorbidity Index score & -6.23 & 0.80 & -7.84 & $<0.0001$ \\
\hline
\end{tabular}

Notes: ${ }^{\dagger}$ Reference group is the low-risk population; ${ }^{\circledR}$ reference group is female; ${ }^{\star}$ reference group is over the age of 65 ; *reference group is the West region.

the low adherence rates typically seen with hypertensive patients. ${ }^{20-22}$ The similar PDC among the three risk groups despite the differences in age, types of comorbid conditions, and Charlson comorbidity index score is probably attributable to the fact that all groups used a similar number of antihypertensive medications (range, $1.34-1.74$ per person) and thereby paid similar costs (range, US\$93-US\$103 per person).

No gold standard has been established for measuring patient adherence to medications. ${ }^{23-28}$ The reliability and validity of using prescription claims data to assess medication adherence have been demonstrated in numerous studies, and claims data have been shown to be more comprehensive than documentation of prescription use in medical records. ${ }^{29-32}$ Furthermore, claims data are more accessible and less expensive than other medication-adherence measurements. ${ }^{33}$

Similar to our study, the relationship between patient cost sharing and adherence has been examined in creative ways using payer claims databases, while others have used databases to evaluate the outcomes of more naturalistic situations. One such study compared medication adherence at four Veterans Affairs medical centers between veterans who were exempt from copayments and propensity-matched veterans who were not exempt. ${ }^{13}$ Over 3500 veterans with hypertension were included in the analysis. The authors reported that increasing copayments from US\$2 to US\$7 had an adverse impact on adherence for veterans treated with antihypertensive medications. Yoon and Ettner ${ }^{11}$ conducted a cross-sectional study of 83,893 commercially insured patients with hypertension using claims data and evaluated the impact of cost sharing on adherence to antihypertensive drugs across varying adherence levels. They concluded from the results of their analyses that cost sharing (copayments or coinsurance) had a substantial negative association with adherence (as determined by medication possession ratio [MPR]) among patients with low adherence to their medication, but the association between cost sharing and higher adherence levels was weak.

Our study provides additional support for the relationship between patient cost sharing and adherence. We sought an approach not previously taken by creating risk groups and subsequently controlling the potentially confounding effect of risk group membership in our models. This also allowed us to examine the independent effect of risk group membership on our outcomes to determine whether an association was present. The independent association between risk group membership and PDC by antihypertensive medication was positive and significant for those patients designated as "high risk" by 3 days. These patients not only had hypertension, they also had a diagnosis of coronary artery disease, chronic kidney disease, diabetes, or ischemic stroke. We also took our 
analysis a few steps further than what had previously been done in the literature by examining whether PDC (adherence) for antihypertensive medication had an effect on resource utilization and health care expenditures. We found a negative and consistent relationship (decrease in $\mathrm{PDC}=$ increase in resource utilization and costs), which should be further evidence of the importance of adherence among patients with hypertension and of particular interest to employers and health plans.

Limitations inherent to claims-based analyses, as well as limitations specific to this study, must be taken into account when considering the results of the analyses. Claims data are collected for the purpose of payment and not research, and are subject to possible coding errors, undercoding, and coding for the purpose of ruling out a suspected disease rather than determining the actual disease. Furthermore, when using prescription claims data to study adherence to medication, it should be noted that a claim does not equate to proof that a medication was taken, or that it was taken as prescribed.

With regard to study-specific limitations, the variables used to define and categorize patients into risk groups were based on claims data with its inherent limitations and were validated with any clinical data that would be obtained only from medical records. Second, given the number of medications that hypertensive patients take (which on average was $\sim 2$ ), our definition of adherence merely measured the number of days within the follow-up period that a patient was "covered" by an antihypertensive medication prescription, accounting for any overlaps for multiple medications. Thus, we were not able to report more standard measures such as the MPR.

\section{Conclusion}

This study assessed the impact of patient cost sharing for antihypertensive medications among commercially insured individuals assigned to different risk categories on the PDC by antihypertensive medications, medical utilization, and health care expenditures. We found an association between higher patient cost sharing and decreased PDC as well as a beneficial association between PDC and various economic outcomes. An increase in PDC was associated with a decrease in both all-cause and hypertension-related utilization of inpatient, outpatient, and emergency room visits as well as medical, pharmacy, and total costs. The current study illustrates the potential untoward effects of higher patient cost sharing among patients with hypertension. Furthermore, the study found that a decrease in PDC is predictive of higher resource utilization and health care costs, which should be of interest to payers and employers alike.

\section{Acknowledgment}

This study was funded by Daiichi Sankyo.

\section{Disclosure}

The authors report no conflicts of interest in this work.

\section{References}

1. Yoon SS, Ostchega Y, Louis T; Centers for Disease Control and Prevention. Recent trends in the prevalence of high blood pressure and its treatment and control, 1999-2008. NCHS Data Brief No. 48; Oct 2010. Available at: http://www.cdc.gov/nchs/data/databriefs/db48. pdf. Accessed December 21, 2011.

2. Centers for Disease Control and Prevention. Diseases and Conditions. Available at: http://www.cdc.gov/DiseasesConditions/. Accessed August 26, 2011.

3. Vasan RS, Beiser A, Seshadri S, et al. Residual lifetime risk for developing hypertension in middle-aged women and men: The Framingham Heart Study. JAMA. 2002;287(8):1003-1010.

4. Lloyd-Jones D, Adams RJ, Brown TM, et al. Heart Disease and Stroke Statistics - 2010 Update. A Report from the American Heart Association Statistics Committee and Stroke Statistics Subcommittee. Circulation. 2010;121(7):948-954.

5. Sokol MC, McGuigan KA, Verbrugge RR, Epstein RS. Impact of medication adherence on hospitalization risk and healthcare cost. Med Care. 2005;43(6):521-530.

6. Rosendorff C, Black HR, Cannon CP, et al. Treatment of hypertension in the prevention and management of ischemic heart disease: A scientific statement from the American Heart Association Council for High Blood Pressure Research and Councils in Clinical Cardiology and Epidemiology and Prevention. Circulation. 2007;115(21):2761-2788.

7. Copley JB, Rosario R. Hypertension: a review and rationale of treatment. Dis Mon. 2005;51(10-11):548-614.

8. Schroeder K, Fahey T, Ebrahim S. Interventions for improving adherence to treatment in patients with high blood pressure in ambulatory settings. Cochrane Collaboration. Available at: http://onlinelibrary.wiley.com/ doi/10.1002/14651858.CD004804/. Accessed January 9, 2012.

9. Burnier M. Medication adherence and persistence as the cornerstone of effective antihypertensive therapy. Am J Hypertens. 2006;19(11):1190-1196.

10. Huskamp HA, Deverka PA, Epstein AM, et al. The effect of incentivebased formularies on prescription-drug utilization and spending. $N$ Engl J Med. 2003;349(23):2224-2232.

11. Yoon J, Ettner SL. Cost sharing and adherence to antihypertensives for low and high adherers. Am J Manag Care. 2009;15(11):833-840.

12. Chernew ME, Shah MR, Wegh A, et al. Impact of decreasing copayments on medication adherence within a disease management environment. Health Aff (Millwood). 2008;27(1):103-112.

13. Maciejewski ML, Bryson CL, Perkins M, et al. Increasing copayments and adherence to diabetes, hypertension, and hyperlipidemic medications. Am J Manag Care. 2010;16(1):e20-e34.

14. Gibson TB, Wang S, Kelly E, et al. A value-based insurance design program at a large company boosted medication adherence for employees with chronic illnesses. Health Aff (Millwood). 2011;30(1):109-117.

15. Maciejewski ML, Farley JF, Parker J, Wansink D. Copayment reductions generate greater medication adherence in targeted patients. Health Aff (Millwood). 2010;29(11):2002-2008.

16. Curtiss FR. Hypertension, prescription drug copayments, and drug therapy adherence. J Manag Care Pharm. 2003;9(5):454-456.

17. Milliman, Inc, Health Cost Guidelines. Available at: http://www. milliman.com/expertise/healthcare/products-tools/health-cost-guidelines/. Accessed December 21, 2011.

18. Doshi JA, Zhu J, Lee BY, et al. Impact of a prescription copayment increase on lipid lowering medication adherence in veterans. Circulation. 2009;119(3):390-397. 
19. Houy M. Value-based benefit design: a purchaser guide [Internet]. Washington (DC): National Business Coalition on Health; 2009 Jan [cited August 26, 2010]. Value-based Benefit Design: a purchaser guide. Available at: http:/www.sph.umich.edu/vbidcenter/ publications/pdfs/VBBDPurchaserGuide\%5B1\%5D.pdf. Accessed December 21, 2011.

20. Nichol MB, Knight TK, Priest JL, et al. Nonadherence to clinical practice guidelines and medications for multiple chronic conditions in a California Mediaid population. J Am Pharm Assoc. 2010;50(4): 496-507.

21. Elliott WJ. Optimizing medication adherence in older persons with hypertension. Urol Nephrol. 2003;35(4):557-562.

22. Wogen J, Krellick CA, Livornese RC, et al. Patient adherence with amlodipine, lisinopril, or valsartan therapy in a usual-care setting. J Manag Care Pharm. 2003;9(5):424-429.

23. Pladevall M, Williams LK, Potts LA, et al. Clinical outcomes and adherence to medications measured by claims data in patients with diabetes. Diabetes Care. 2004;27(12):2800-2805.

24. DiMatteo MRP. Variations in patients' adherence to medical recommendations: a quantitative review of 50 years of research. Med Care. 2004;42(3):200-209.

25. Dunbar-Jacob J, Mortimer-Stephens MK. Treatment adherence in chronic disease. J Clin Epidemiol. 2001;54(Suppl 1):S57-S60.

26. Ellis S, Shumaker S, Sieber W, Rand C. Adherence to pharmacological interventions: current trends and future directions: the Pharmacological Intervention Working Group. Control Clin Trials. 2000;21(Suppl 5): S218-S225.

27. Turner BJ, Hecht FM. Improving on a coin toss to predict patient adherence to medications. Ann Intern Med. 2001;134(10):1004-1006.
28. Vitolins MZ, Rand CS, Rapp SR, Ribisl PM, Sevick MA. Measuring adherence to behavioral and medical interventions. Control Clin Trials. 2000;21(5 Suppl):S188-S194.

29. Lau HS, de Boer A, Beuning KS, Porsius A. Validation of pharmacy records in drug exposure assessment. J Clin Epidemiol. 1997;50(5): 619-625.

30. Johnson RE, Volmer WM. Comparing sources of drug data about the elderly. J Am Geriatr Soc. 1991;39(11):1079-1084.

31. Steiner JF, Prochazka AV. The assessment of refill compliance using pharmacy records: Methods, validity, and applications. J Clin Epidemiol. 1997;50(1):105-116.

32. Kirking DM, Ammann MA, Harrington C. Comparison of medical records and prescription claims files in documenting prescription medication therapy. J Pharmacoepidemiol. 1996;5(1):3-15.

33. Fairman K, Motheral B. Evaluating medication adherence: Which measure is right for your program? J Manag Care Pharm. 2000;6(6): 499-502.

34. Nair KV, Wolfe P, Valuck RJ, McCollum MM, Ganther JM, Lewis SJ. Effects of a 3-tier pharmacy benefit design on the prescription purchasing behavior of individuals with chronic disease. JManag Care Pharm. 2003;9(2):123-133.

35. Goldman DP, Joyce GF, Zheng Y. Prescription drug cost sharing. JAMA. 2007;298(1):61-69.

36. Charlson ME, Pompei P, Ales KL, MacKenzie CR. A new method of classifying prognostic comorbidity in longitudinal studies: development and validation. J Chron Dis. 1987;40(5):373-383.
Patient Preference and Adherence

\section{Publish your work in this journal}

Patient Preference and Adherence is an international, peer-reviewed, open access journal focusing on the growing importance of patient preference and adherence throughout the therapeutic continuum. Patient satisfaction, acceptability, quality of life, compliance, persistence and their role in developing new therapeutic modalities and compounds to

\section{Dovepress}

optimize clinical outcomes for existing disease states are major areas of interest. This journal has been accepted for indexing on PubMed Central. The manuscript management system is completely online and includes a very quick and fair peer-review system. Visit http://www.dovepress.com/ testimonials.php to read real quotes from published authors. 